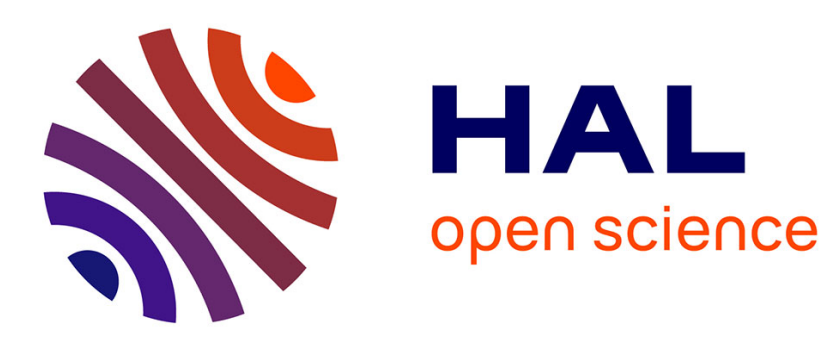

\title{
UV irradiation influence on the structural and optical properties of $\mathrm{CdO}$ thin films
}

\author{
C. Dantus, D. Timpu, D. Luca, F. Iacomi
}

\section{To cite this version:}

C. Dantus, D. Timpu, D. Luca, F. Iacomi. UV irradiation influence on the structural and optical properties of $\mathrm{CdO}$ thin films. European Physical Journal: Applied Physics, 2011, 55 (1), pp.10301. 10.1051/epjap/2011110055 . hal-00719815

\section{HAL Id: hal-00719815 \\ https://hal.science/hal-00719815}

Submitted on 21 Jul 2012

HAL is a multi-disciplinary open access archive for the deposit and dissemination of scientific research documents, whether they are published or not. The documents may come from teaching and research institutions in France or abroad, or from public or private research centers.
L'archive ouverte pluridisciplinaire HAL, est destinée au dépôt et à la diffusion de documents scientifiques de niveau recherche, publiés ou non, émanant des établissements d'enseignement et de recherche français ou étrangers, des laboratoires publics ou privés. 


\title{
UV irradiation influence on the structural and optical properties of CdO thin films
}

\author{
C. Dantus ${ }^{\mathrm{a}^{*}}$, D. Timpu ${ }^{\mathrm{b}}$, D. Luca ${ }^{\mathrm{a}}, \mathrm{F} \cdot$ Iacomi $^{\mathrm{a}}$ \\ „„Al. I. Cuza” University, 11 Carol I Bldv, RO-700506, Iasi, Romania \\ ${ }^{b}$ Institute of Macromolecular Chemistry "Petru Poni," Aleea Gr. Ghica-Voda nr. \\ 41A., 6600, Iassy, Romania
}

\begin{abstract}
Polycrystalline Cd thin films were evaporated in a vacuum onto glass substrates at $\mathrm{Cd}$ source temperature of $770 \mathrm{~K}$. The as-deposited Cd films were subjected to a gradual heating at the rate of $5 \mathrm{~K} / \mathrm{min}$, up to a temperature of $650 \mathrm{~K}$ and were then maintained at this temperature for $5 \mathrm{~min}$. Then, the respective samples were cooled down to room temperature at the same rate. The obtained $\mathrm{CdO}$ thin films were UV irradiated for $2 \mathrm{~h}$ (150W mercury lamp, 3.18-3.65 eV). By means of XRD, AFM and XPS techniques, the structural characteristics of the typical obtained CdO samples before and after UV treatment were been investigated. The obtained results indicate that the UV treatment induces a recrystallisation process: changes in sample morphology, surface roughness and crystallite size and orientation. XRD and XPS studies evidenced an improvement in crystalline structure and stoichiometry. UV irradiated sample shows photo-catalytic properties.
\end{abstract}

Keywords: UV irradiation; cadmium oxide; optical properties; structure;

\section{Introduction}

Transparent conducting oxides (TCO) thin films have attracted great interest in recent years because of their unique chemical and physical properties, which are different from those of either bulk materials or single atoms. In recent years, researchers have focused on cadmium oxide (CdO) due to its applications, specifically in the field of optoelectronic devices such as solar cells, photo transistors and diodes, transparent electrodes and gas sensors [1].

* Corresponding author: dantuscristian@uaicphys.co.cc 
Cadmium Oxide (CdO) thin films are regarded as materials with many attractive properties such as a large energy band gap (bulk CdO is an n-type broad band gap semiconductor, with a direct band gap of $2.3 \mathrm{eV}$ and an indirect band gap of $1.36 \mathrm{eV}$ ), high transmission coefficient in visible spectral domain and remarkable luminescence characteristics.

In the last ten years, the electrical and optical properties of $\mathrm{CdO}$ thin films prepared by various techniques such as spray pyrolysis [2], oxidation of cadmium films [3], metal organic chemical vapour deposition (MOCVD) [4], sol-gel [5], sputtering [6], vacuum evaporation [7] and reactive pulsed laser deposition [8]. have been studied. It was experimentally established that these properties are very sensitive to the film structure and deposition conditions. The intensity of optical and electrical effects of CdO depends on the deviations from the ideal CdO stoichiometry, as well as on the size and shape of the particles.

Some recent studies [9-12] evidenced that the main effects of UV irradiation on thin films are variations of thickness, chemical composition and structure, leading to changes in their electrical and optical properties. Bradford et al. [11,12] observed changes in the optical properties of silicon oxide thin films and attributed these changes due to an increase of oxygen molecules or atoms in the deposited films during their exposure to UV irradiation in the air. The UV light excites electrons from the valence to the conduction band, leaving holes behind. The photo-generated electron-hole pairs which migrate to its surface can initiate redox reactions with the surface species [10,13,14]. Fernández-Rodríguez et al. [10] observed that two different and independent processes occur when $\mathrm{TiO}_{2}$ films are exposed to UV irradiation: changes in the contact angle. These changes, mainly affect the surface of the films and the rearrangement and incorporation of oxygen is likely to occur in the bulk of the material. We wonder whether such a change caused by UV irradiation would also bring some influence on its other properties. The objective of this paper is to discuss the effect of UV irradiation on the structure and optical properties of CdO thin films.

\section{Experimental}

Cd thin films were obtained by thermal evaporation under a vacuum of metallic cadmium pellets of $99.99 \%$ purity at an evaporation source temperature of $770 \mathrm{~K}$. The residual pressure in the standard vacuum equipment was about $1.3 \times 10^{-}$ 
${ }^{3} \mathrm{~Pa}$. Microscope cleaned glass slides of $1.5 \mathrm{~cm}$ x1.5 cm x $0.2 \mathrm{~cm}$ dimensions were used as substrates. No heating system for the substrates during film deposition was used. The film growth rate ranged between 4.0 and $4.5 \mathrm{~nm} / \mathrm{s}$. The source - substrate distance was $15 \mathrm{~cm}$. A special substrate holder permits six samples to be obtained simultaneously in the same deposition conditions.

The as obtained Cd metallic thin films were subsequently oxidised by heating in air in ambient conditions of up to a temperature of $650 \mathrm{~K}$. The reports on the physical properties of other oxide films prepared by thermal oxidation of metallic films revealed a strong dependence of these properties on the heating rate during the oxidation process. The as-deposited $\mathrm{Cd}$ films were subjected to a gradual heating with the rate of $5 \mathrm{~K} / \mathrm{min}$. up to a temperature of $650 \mathrm{~K}$ and were maintained at this temperature for $5 \mathrm{~min}$. Then, the respective samples were cooled down to room temperature at the same rate. During the heating process, the colour of the Cd films changed from silver-grey at room temperature to a red colour at a temperature of $650 \mathrm{~K}$.

In order to study the influence of the UV radiation on structure and optical properties of as-obtained thin films, a 150W (3.18-3.65 eV) mercury lamp was used. The UV irradiation process was performed in open air for $2 \mathrm{~h}$.

The thickness of $\mathrm{CdO}$ films, determined by using an interferential microscope, was found to be $360 \mathrm{~nm}$. The film crystalline structure was investigated using the standard X-ray diffraction (XRD) technique, with BRUKER $8 \mathrm{D}, \mathrm{CuK}_{\alpha}(\lambda=0.154 \mathrm{~nm})$ in the $2 \theta$ range $20^{\circ}-80^{\circ}$. Thin film surface morphology was studied using an atomic force microscope, model NT-MDT Solver Pro. Cadmium oxide thin films composition has been studied using an x-ray photoelectron microscope, model PHI 5000 VersaProbe. For optical measurements, transmittance spectra corrected for the effect of glass substrates were acquired in the wavelength range $400 \mathrm{~nm}-1800 \mathrm{~nm}$ using a computer controlled UV-VIS-NIR spectrometer type Tech5 AG.

\section{Results and discussion}

In Fig. 1 the typical patterns for both as-obtained and UV treated CdO films are shown. From respective XRD patterns one can conclude that both films are polycrystalline. The as obtained $\mathrm{CdO}$ films are characterised by a strong X-ray peak at $2 \theta=33.201^{\circ}$ (Fig.1 a) which corresponds to (111) the diffraction plane of the CdO face centred (FCC) cubic structure The UV treated CdO films are characterised by a strong X-ray peak at $2 \theta=33.09^{\circ}$ (Fig. $1 \mathrm{~b}$ ) also corresponding to 
the (111) diffraction plane. This indicates the preferential (111) orientation of the CdO film grains in both cases.

As can be seen, the respective patterns exhibit diffraction peaks characteristic to the CdO face centred (FCC) cubic structure. This reveals that pure CdO was formed during Cd film annealing.
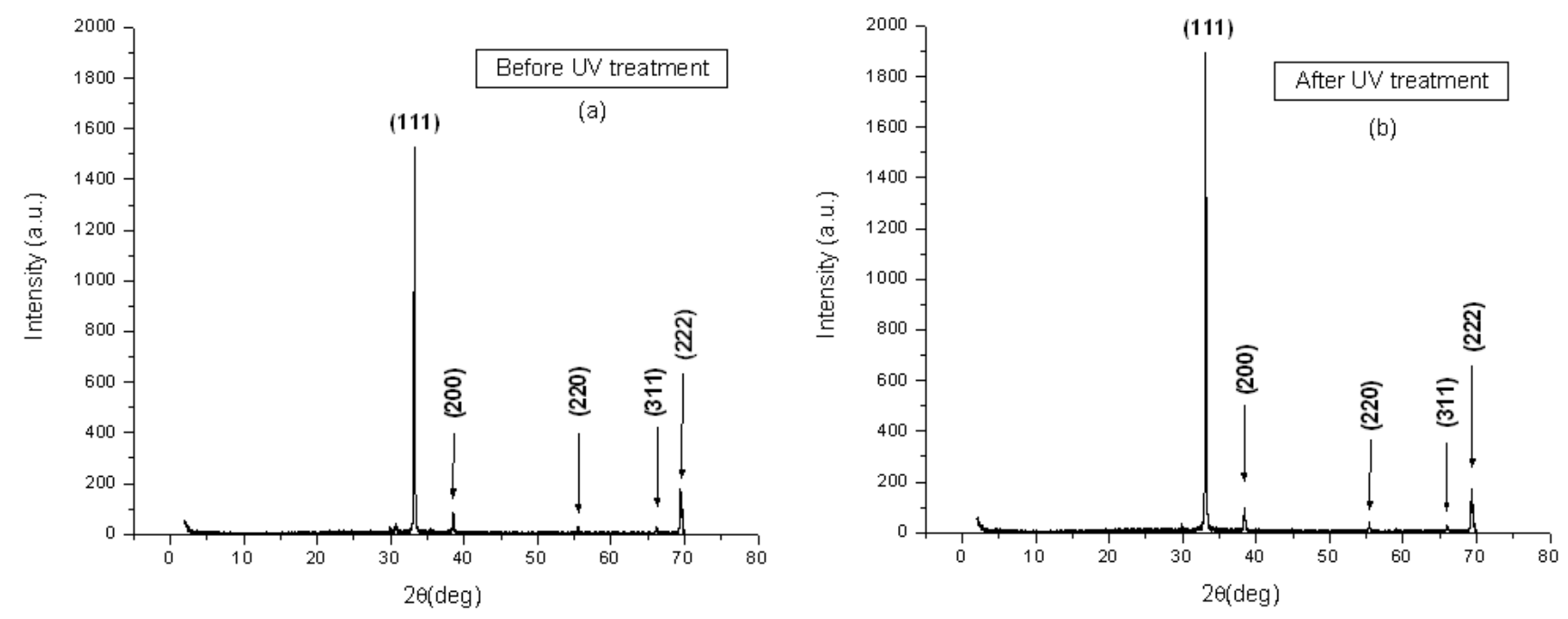

Fig. 1. XRD for CdO thin film (a) -before UV treatment (b) - after UV treatment

XRD patterns for as obtained and UV irradiated samples show changes in intensity and peak positions. An increase in unit cell parameter value was evidenced.

\begin{tabular}{|c|c|c|c|c|c|}
\hline \multirow{2}{*}{ Sample } & \multicolumn{5}{|c|}{$\mathbf{2 0}_{\text {(hkl) }}$} \\
\cline { 2 - 6 } & $\mathbf{( 1 1 1 )}$ & $\mathbf{( 2 0 0 )}$ & $\mathbf{( 2 2 0 )}$ & $\mathbf{( 3 1 1 )}$ & $\mathbf{( 2 2 2 )}$ \\
\hline Standard CdO & 33.030 & 38.318 & 55.308 & 65.972 & 69.353 \\
\hline as-obtained CdO & 33.20 & 38,48 & 55,50 & 66,13 & 69,47 \\
\hline UV treated CdO & 33,09 & 38.38 & 55.35 & 66,02 & 69.32 \\
\hline
\end{tabular}

Table 1 Values of the diffraction angles and planes for cadmium oxide before and after UV treatment $\mathbf{2 \theta}_{(\mathbf{h k l})}$ - X-ray peak corresponding to (hkl) diffraction plane 
The values of some structural parameters determined for analysed CdO samples are summarised in Table 2.

The texture coefficient TC (hkl) which describes the preferred orientation of the crystallites in respective samples was calculated using the expression $[15,16]$ :

$$
T C(h k l)=\frac{I(h k l) / I_{0}(h k l)}{N^{-1} \sum I(h k l) / I_{0}(h k l)}
$$

where TC(hkl) is the texture coefficient of the (hkl) plane, I and $I_{0}$ denote the measured and ASTM standard intensities of the (hkl) maxima, respectively, and N is the number of the reflections in diffraction patterns. From Table 2 one can see that the calculated values of $\mathrm{TC}(\mathrm{hkl})$ are deviated from unity, especially those corresponding to (111) and (222) planes, which have supraunitary values. This indicates that the respective films have the largest preferred crystallographic orientation along the (111) and (222) diffraction planes, which increase for the (111) plane and decreases for (222) plane with UV treatment. Such higher values for the texture coefficient have also been reported by F.C. Eze for reactive vacuum evaporated CdO films deposited at various partial pressure of oxygen [17]. So, one can conclude that similar growth mechanism of the CdO crystallites occurs in both cases (of CdO films obtained by thermal oxidation of vacuum evaporated Cd films and of those obtained by reactive vacuum evaporation).

\begin{tabular}{|c|c|c|c|c|c|c|}
\hline $\begin{array}{c}\text { Structural } \\
\text { parameters }\end{array}$ & & $\mathbf{( 1 1 1 )}$ & $\mathbf{( 2 0 0 )}$ & $\mathbf{( 2 2 0 )}$ & $\mathbf{( 3 1 1 )}$ & $\mathbf{( 2 2 2 )}$ \\
\hline \multirow{2}{*}{$\mathbf{a}(\mathbf{h}, \mathbf{k}, \mathbf{l})$} & before & 4.68 & 4.68 & 4.70 & 4.68 & 4.68 \\
\cline { 2 - 7 } & after & 4.69 & 4.70 & 4.70 & 4.70 & 4.71 \\
\hline \multirow{2}{*}{$\mathbf{d}(\mathbf{h}, \mathbf{k}, \mathbf{l})$} & before & 2.70 & 2.34 & 1.66 & 1.41 & 1.35 \\
\cline { 2 - 7 } & after & 2.71 & 2.35 & 1.66 & 1.42 & 1.36 \\
\hline \multirow{2}{*}{$\mathrm{TC}(\mathbf{h}, \mathbf{k}, \mathbf{l})$} & before & 2.42 & 0.16 & 0.12 & 0.15 & 2.15 \\
\cline { 2 - 7 } & after & 2.71 & 0.16 & 0.14 & 0.14 & 1.85 \\
\hline $\mathbf{I}_{\text {before }} / \mathbf{I}_{\text {after }}$ & - & 0.80 & 0.87 & 0.76 & 0.97 & 1.05 \\
\hline
\end{tabular}

Table 2 Lattice parameter (a), interplanar distance (d), texture coefficient (TC) and relative intensity calculated for cadmium oxide before and after UV treatment $a(h k l)$ - lattice parameter, $d(h k l)$ - interplanar distance, $T C(h k l)$ - texture coefficient, $I_{\text {before }} / I_{\text {after }}$ - relative intensity of the peaks 
Using the well-known Bragg formula [18] the lattice parameter "a” for CdO cubic structure was evaluated for each diffraction planes from Fig. 1 (a,b). The obtained values ranged between $4.68 \AA$ and $4.71 \AA$ and are around the standard value of $4.695 \AA$ [19]. This indicates the presence of a compressive stress in the films, produced by different factors such as impurities, lattice defects, vacancies and deformation faults $[18,20,21]$. The shift towards higher $2 \theta$ values of the diffraction maxima relative to their normal positions, as it results from Table 1 , confirms the above assumption. Similar shifts of the diffraction maxima have been also noticed by other authors for CdO thin films prepared by spray pyrolysis [22, 23] and by reactive vacuum evaporation [17]. The shifts were attributed to the lattice contraction. In addition, the oxygen vacancies can be responsible for the lower value of the lattice parameter [25]. After UV treatment, it can be seen that the lattice parameter increases, suggesting a reorientation of the crystallites.

Medium crystallite size for both samples were calculated: $\mathrm{D}_{\text {(before) }}=608.86$ $\mathrm{nm}$ and $\mathrm{D}_{\text {(after) }}=469.83 \mathrm{~nm}$.

The true value, $\mathrm{a}_{0}$, of the lattice parameter for our typical CdO samples have been determined by plotting of the lattice parameter, calculated for each peak from XRD patterns versus the function Nelson-Riley (NRF) defined by the expression $[16,22,25]$ :

$$
N R F=\frac{1}{2}\left(\frac{\cos ^{2} \theta}{\sin \theta}+\frac{\cos ^{2} \theta}{\theta}\right)
$$

where $\theta$ is the Bragg angle. 


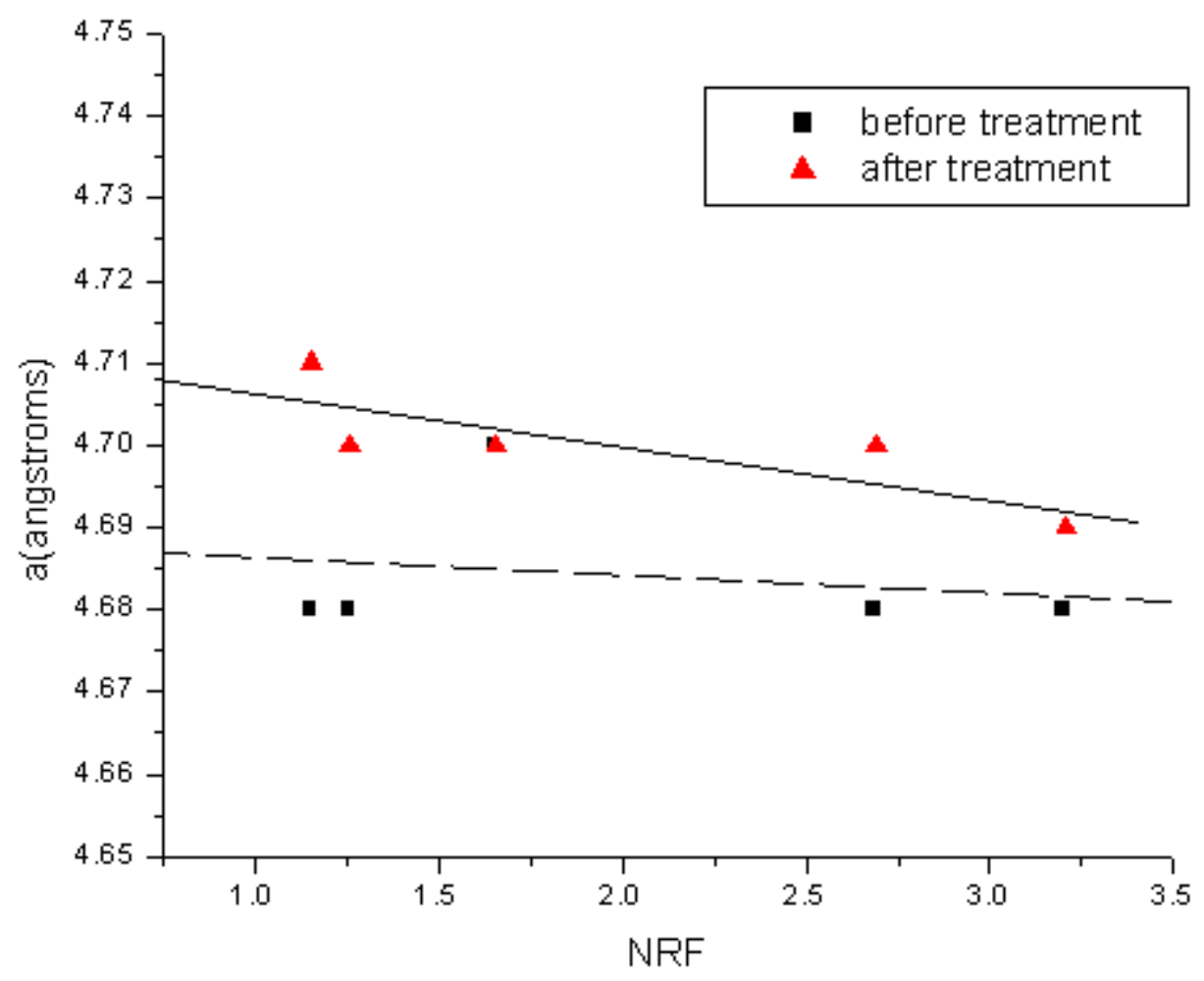

Fig. 2. Nelson-Riley plots of the lattice parameter for typically studied CdO samples

Fig 2. shows the "a" versus NRF plots obtained for the analysed CdO samples. By extrapolating the lines to $\mathrm{NRF}=0$, the true lattice parameter, $\mathrm{a}_{0}$, for respective CdO films was obtained: $\mathrm{a}_{\text {(before treatment) }}=4.69 \AA, \mathrm{a}_{\text {(after treatment) }}=4.71 \AA$. The summarised values are close to bulk $\mathrm{CdO}$. The different values suggest the existence of a mechanical stress.

Fig. 3 depicts a selection of ( $3 \mu \mathrm{m} \times 3 \mu \mathrm{m}) 2 \mathrm{D}$ and 3D AFM images of the typically studied $\mathrm{CdO}$ thin films. One can observe that the crystallites of the $\mathrm{CdO}$ sample before the UV treatment are oriented in order to make an angle with the surface normal smaller than 90 degrees. After the treatment, it can be seen that the crystallites have a preferential orientation over the $\mathrm{O}_{z}$ axis. The UV radiation determines a recrystallisation process, also evidenced by the increase in the roughness of the treated sample. 

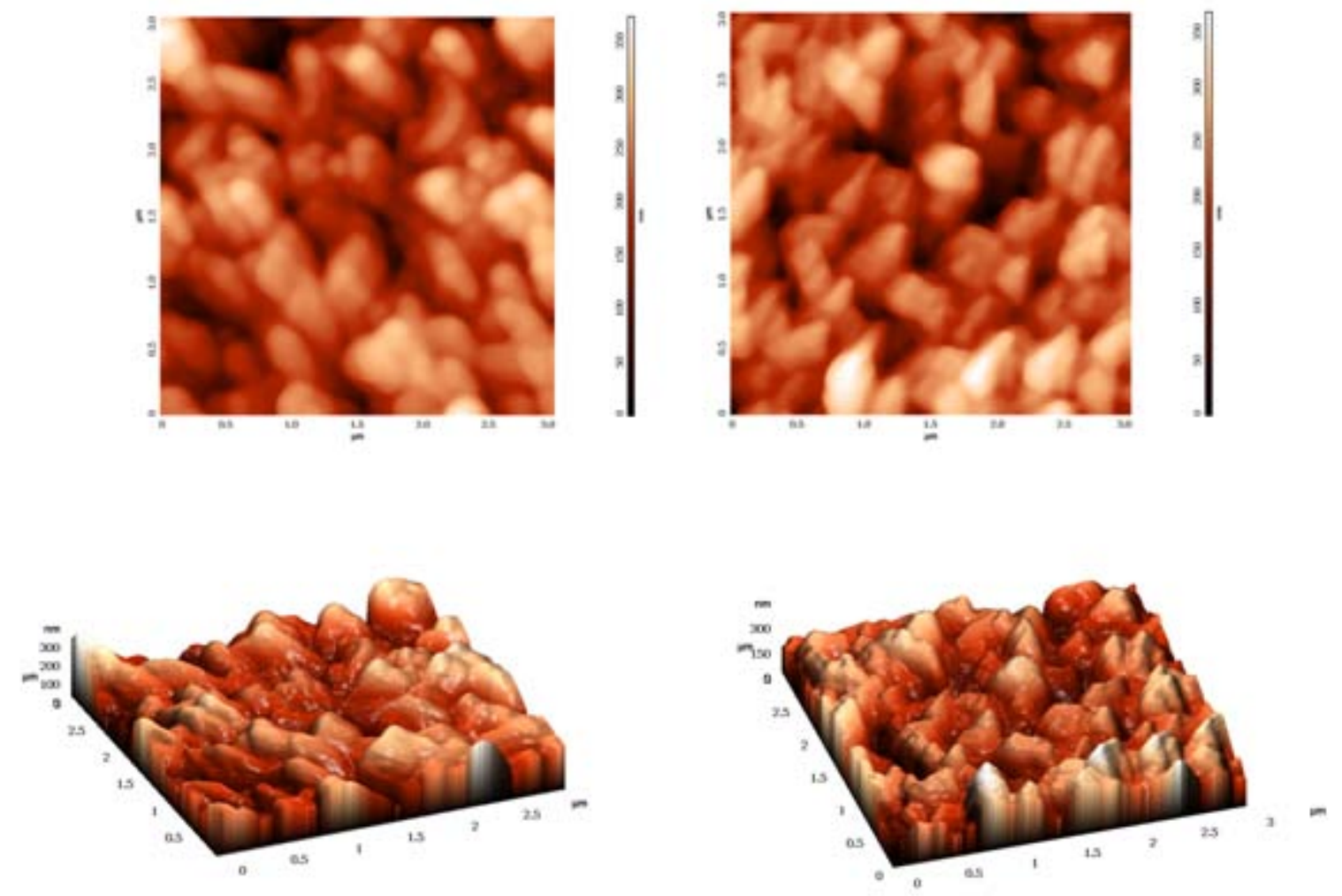

a)

b)

Fig. 3 AFM micrographs (3x3 $\mu \mathrm{m})$ for CdO thin films: (a) - before UV treatment $\left(R_{r m s}=43.93 \mathrm{~nm}\right)$; (b) - after UV treatment $\left(R_{r m s}=50.49 \mathrm{~nm}\right)$

Since it is confirmed that the film's properties depends on the crystal structure, XPS analysis was performed for the CdO films in order to study the chemical states before and after UV treatment.

Figures 4 and 5 shows the XPS survey scan of the as-deposited film (a) and UV treated sample (b) with the (111) texture. The atomic composition was calculated from the XPS survey scan and found to be Cd $71 \%$, O $29 \%$ for the untreated sample and Cd 50.1\%, O 49.9\% for the sample after the UV treatment. 

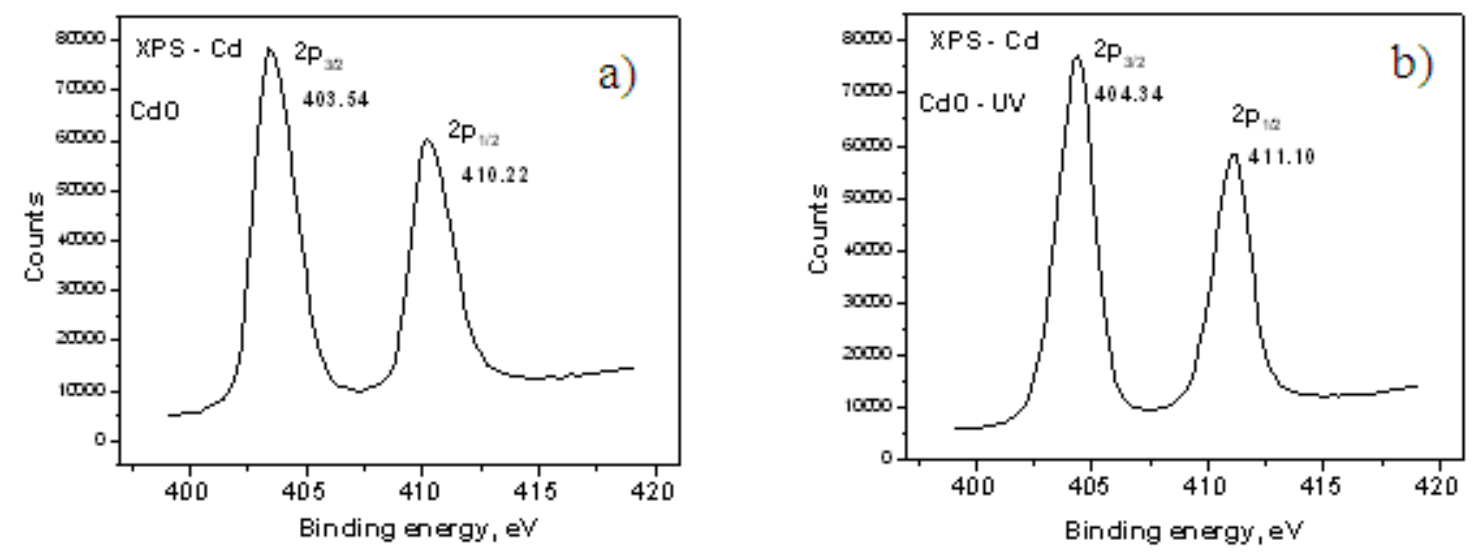

Fig. 4 XPS of Cd in CdO thin film (a) -before UV treatment $\mathrm{CdO}_{1-\mathrm{x}}, \mathrm{x}=0.7$ (b) after UV treatment, $\mathrm{CdO}_{1-\mathrm{x}}$

XPS spectra of UV irradiated sample show a shift to higher energies. 2p XPS peaks of $\mathrm{Cd}$ and 1s XPS peak of $\mathrm{O}$ can be attributed to $\mathrm{Cd}-\mathrm{O}$ bonding in CdO. XPS peak at $530 \mathrm{eV}$, attributed to $\mathrm{O}_{2}$ species adsorbed on the surface, strongly increases after UV irradiation.
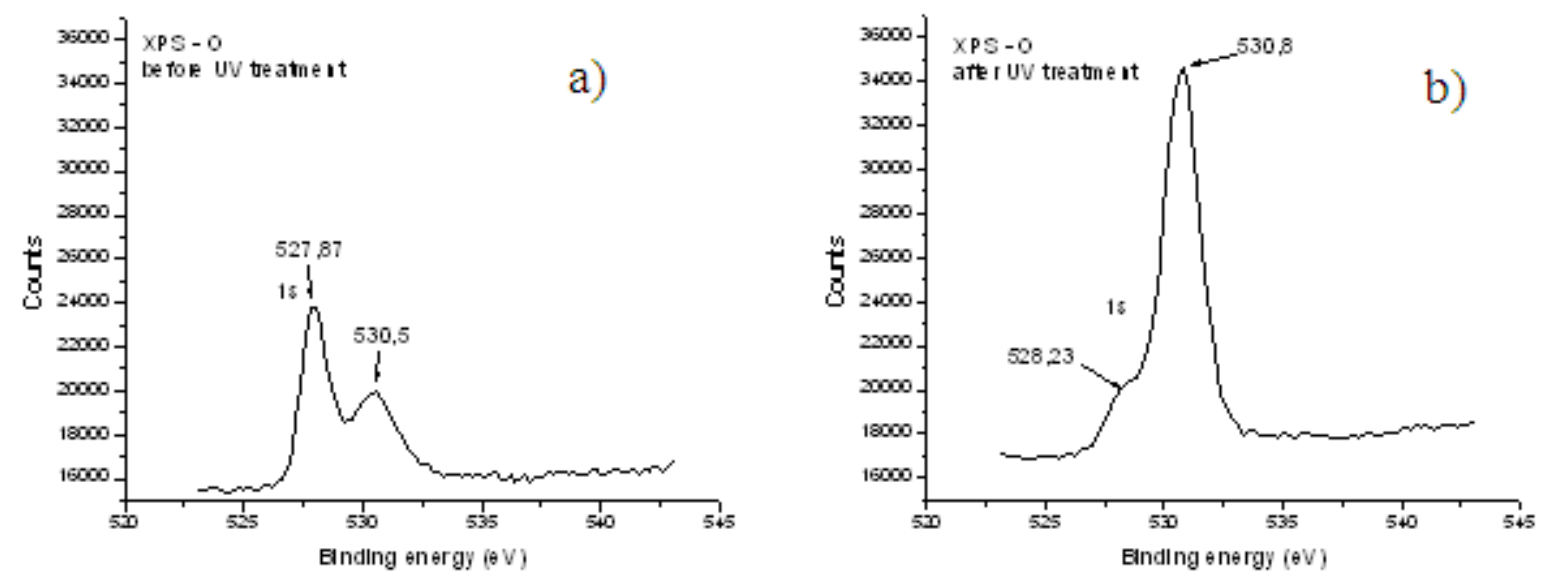

Fig. 5 XPS of O in CdO thin film (a) -before UV treatment (b) - after UV treatment 
In Fig. 6, the typical transmission spectra in the wavelength range $400 \mathrm{~nm}-$ $1800 \mathrm{~nm}$ for the as-obtained CdO film and UV treated sample are shown.
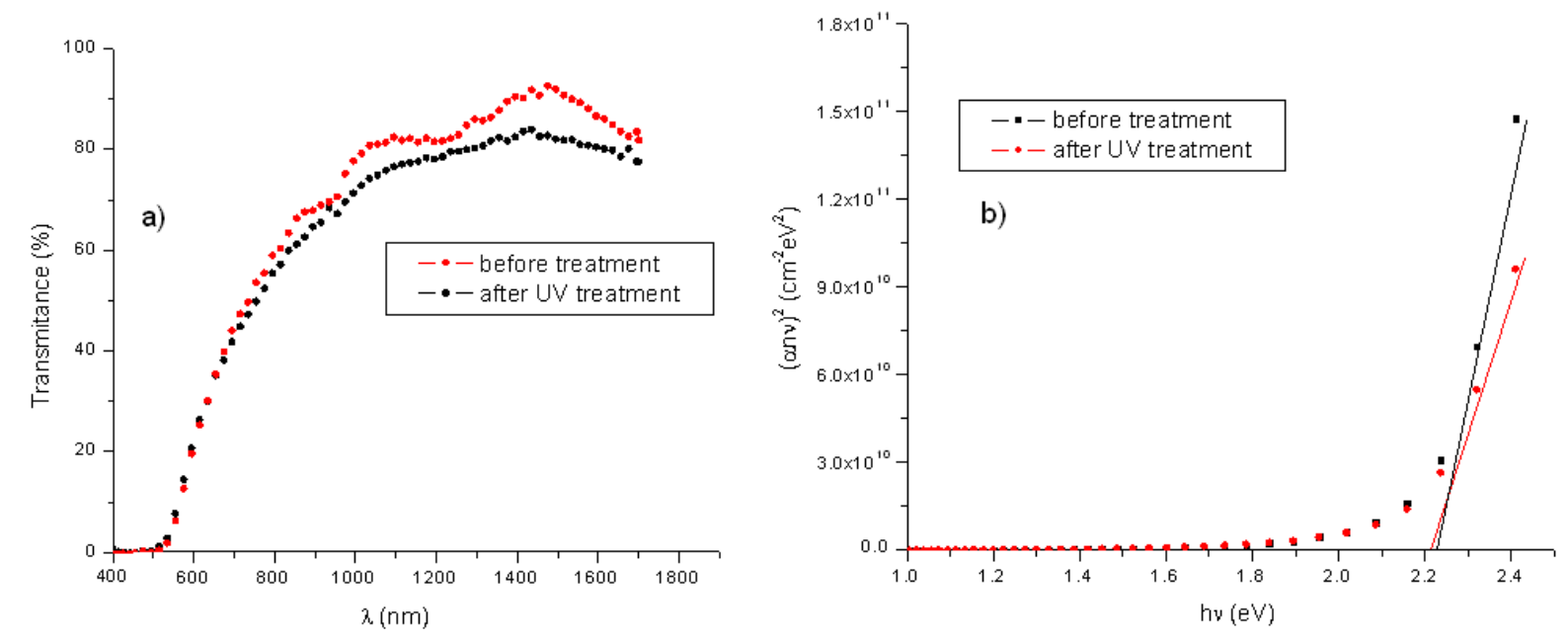

Fig. 6 Effect of the UV treatment on the optical transmittance for CdO thin films

(a) transmittance of both untreated and UV irradiated samples (b) - bandgap calculus

A clean glass substrate was used as a reference for transmittance measurements. All the studied samples were transparent (almost 90\%); a small diminution in the optical transmittance of UV irradiated samples was observed (80\%). Plotting the dependence $(a h v)^{2}$ vs. $h v$, the optical energy gap for respective transitions can be determined. By extrapolating the linear portion of respective plots to $(a h v)^{2}=0$, the optical band-gap energies for direct and indirect transitions were determined. The value of the optical bandgap was found to be about $2.2 \mathrm{eV}$. No significant variation of the bandgap value has been found. From the literature data, the direct band-gap values for $\mathrm{CdO}$ films prepared by different techniques ranged between 2.2 and $2.8 \mathrm{eV}$ [26,27,28,30,31,33,34]. Similar values of $\mathrm{E}_{\mathrm{g}}\left(2.20^{-}\right.$ $2.29 \mathrm{eV}$ ) were found for $\mathrm{CdO}$ films prepared by spray pyrolysis [32,34] and magnetron sputtering [29].

\section{Conclusions}

CdO thin films, prepared by dry thermal oxidation of metallic Cd thin films deposited by vacuum evaporation, were UV irradiated for 2h (150W mercury lamp, 
3.18-3.65 eV). XRD patterns for UV irradiated samples show changes in intensity and peak positions. An increase in unit cell parameter value was evidenced. The UV radiation determines a recrystallisation process evidenced by the increase in the roughness of the treated sample and changes in the sizes and orientation of the crystallites along the surface normal. XPS spectra of UV irradiated sample shows a shift to higher energies. XPS peak at $530 \mathrm{eV}$, attributed to $\mathrm{O}_{2}$ species adsorbed on surface, strongly increases after UV irradiation. Optical transmittances of the CdO samples have a small decrease after UV treatment. The value of the optical bandgap was found to be about $2.2 \mathrm{eV}$. No significant variation of the bandgap value has been observed.

\section{Acknowledgements}

The authors would like acknowledge to Dr. M. Dobromir, for XPS analyses.

\section{Bibliography}

[1] Y-H Tak, K-B Kim, H-G Park, K-H Lee, J-R Lee, Thin Solid Films 411/1 (2002) 12

[2] S Aksoy, Y Caglar, S Ilican, M Caglar, Int. J. Hydrogen Energy, 34/12 (2009) 5191

[3] C. Dantus, , G.G. Rusu , M. Dobromir, M. Rusu, Appl. Surf. Sci., 255/5 (2008) 2665

[4] A Gulino, G Tabbì, Appl. Surf. Sci., 245/1-4 (2005) 322

[5] D.M. Carballeda-Galicia, R. Castanedo-Pérez, O. Jiménez-Sandoval, S. Jiménez-Sandoval, G. Torres-Delgado, C.I. Zúñiga-Romero, Thin Solid Films, 371/1-2 (2000) 105

[6] Q. Zhou, J. Zi, B. Hu, C. Chen, L. Zhao, C. Wang, Mater. Lett., 61/2 (2007) 531

[7] A. A. Dakhel, F. Z. Henari, Cryst. Res. Technol. 38/11 (2003) 979

[8] Raid A. Ismail, Bassam G. Rasheed , Evan T. Salm, Mukram AlHadethy, J Mater Sci: Mater Electron 18/10 (2007) 1027

[9] M. Purica, F. Iacomi, C. Baban, P. Prepelita, N. Apetroaei, D. Mardare, D. Luca, Thin Solid Films, 515/ 24 (2007) 8674 
[10] M. Fernández- Rodríguez, V. J. Rico, A. R. González-Elipe, and A. Álvarez-Herrero, Phys. stat. sol. (c) 5 (2008) 1164

[11] A. P. Bradford, G. Hass, M. McFarland, and E. Ritter, A. P. Bradford, G. Hass, and M. McFarland, Appl. Opt. 4 (1965) 971

[12] A. P. Bradford and G. Hass, J. Opt. Soc. Am. 53 (1963) 1096

[13] Yunxia Wang, HonglingWang and Fengyuan Yan, Surf. Interface Anal., 41 (2009) 399

[14] Ken-ichi Katsumata, Akira Nakajima, Tadashi Shiota, Naoya Yoshida, Toshiya Watanabe, Yoshikazu Kameshima and Kiyoshi Okada, J. Photochem. Photobiol., A, 180 (2006) 75

[15] C. Baret, T. B. Massalski, Structure of Metals, Pergamon Press, Oxford, 1980

[16] R. J. Deokate, S. M. Pawar, A. V. Moholkar, V. S. Sawant, C. A. Pawar, C. H. Bhosale, K. Y. Rajpure , Appl. Surf. Sci., 254 (2008) 2187

[17] F. C. Eze, Mater. Chem. And Phys. 89 (2005) 205

[18] B. D. Cullity, R. S. Stock, Elements of X-Ray Diffraction, Prentice Hall, 3rd ed, 2001

[19] ASTM X-ray Powder Diffraction Data File, Card 05-640

[20] M. Ohring, The Materials Science of Thin Solid Films, Academic Press, New York, 1992

[21] A.A. Dakhel , F.Z. Henari , Cryst. Res. Technol. 38/11 (2003) 979

[22] K. Gurumurugan, D. Mangalaraj, Sa. K. Narayandass, J. Cryst. Growth, 147 (1995) 355

[23] O. Vigil, F. Cruz, A. Morales-Acevedo, G. Contreras- Puente, L. Vaillant, G. Santana, Mater. Chem. And Phys. 68 (2001) 249

[24] J. Santos-Cruz, G. Torres-Delgado, R. Castanedo- Perez, S. JiménezSandoval, O. Jiménez-Sandoval, C.I. Zúñiga-Romero, J. Marquez Marin, O. Zelaya-Angel , Thin Solid Films, 483 (2005) 83

[25] H. P. Klug, L. E. Alexander, X-Ray Diffraction Procedures for Polycrystalline and Amorphous Materials, Wiley, New York, 1994

[26] B. Saha, S. Das, K.K. Chattopadhyay, Sol. Energy Mater. Sol. Cells 91 (2007) 1692

[27] J. Santos-Cruz, G. Torres-Delgado, R. Castanedo-Perez, S. JiménezSandoval, O. S. Jiménez-Sandoval, C.I. Zuniga-Romero, J. Marquez Marin, O. Zelaya-Angel, Thin Solid Films 483 (2005) 83 
[28] B.J. Lokhandee, P.S. Patil, M.D. Uplane, Mater. Chem. Phys. 84 (2004) 238

[29] P. Mohan Babu, G. Venkata Rao, P. Sreedhara Reddy, S. Uthanna, Mater. Lett. 60 (2006) 274

[30] T.K. Subramanyam, B. Radha Krishna, S. Uthanna, B.S. Naidu, P.J. Reedy, Vacuum 48/6 (1997) 565

[31] A.A. Dakhel, F.Z. Henari, Cryst. Res. Technol. 38/11 (2003) 979

[32] O. Vigil, F. Cruz, A. Morales-Acevedo, G. Contreras-Puente, L. Vaillant, G. Santana, Mater. Chem. Phys. 68 (2001) 249

[33] K. Gurumurugan, D. Mangalaraj, Sa.K. Narayandass, Y. Nakanishi, Mater. Lett. 28 (1996) 307

[34] R.J. Deokate, S.M. Pawar, A.V. Moholkar, V.S. Sawant, C.A. Pawar, C.H. Bhosale, K.Y. Rajpure, Appl. Surf. Sci. 254 (2008) 2187 